\title{
Psychological-Clinical Review on Coronavirus (COVID-19)
}

ISSN: 2637-7748

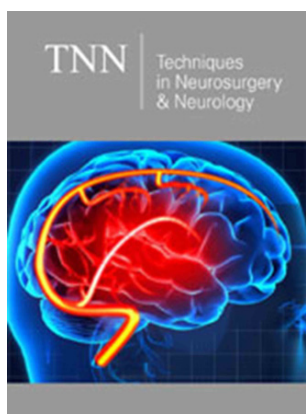

*Corresponding author: Mohammad Qassem Abdullah, Clinical Psychology and Mental Health, Syria

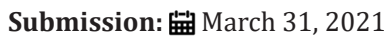

Published: 陋 March 15, 2021

Volume 4 - Issue 1

How to cite this article: Mohammad Qassem Abdullah. Psychological-Clinical Review on Coronavirus (COVID-19). Tech Neurosurg Neurol. 4(1). TNN. 000579. 2021.

DOI: 10.31031/TNN.2021.04.000579

Copyright@ Mohammad Qassem Abdullah, This article is distributed under the terms of the Creative Commons Attribution 4.0 International License, which permits unrestricted use and redistribution provided that the original author and source are credited.

\author{
Mohammad Qassem Abdullah* \\ Clinical Psychology and Mental Health, Syria
}

\section{Coronaviruses}

Every person agree that health is very important and significant for human well-being. Around the turn of the century, people primarily died from infectious disease and die from lifestyle disease which are related to health damaging personal habits and behavior. Familiar example includes heart disease, stroke, and lung cancer. Clearly some behaviors and lifestyle promote health whereas other lead to illness and death. As the cartoon character Pogo put it "we have met the enemy and he is us", Now, the international healthy crisis is coronavirus, that represent the most important challenge to the universal health care services. The infectious disease is stressful event around the world that lead to many negative consequences and effects: heath/medical, political, social, psychological fields. Coronaviruses (CoV) are a large family of viruses that cause illness ranging from the common cold to more severe diseases such as Middle East Respiratory Syndrome (MERS-CoV) and Severe Acute Respiratory Syndrome (SARS-CoV). A respiratory virus that originated in China has infected more than 100,000 people and has begun to spread in the U.S. Coronavirus disease (COVID-19) is a new strain that was discovered in 2019 and has not been previously identified in humans. Coronaviruses are zoonotic, meaning they are transmitted between animals and people. Detailed investigations found that SARS-CoV was transmitted from civet cats to humans and MERS-CoV from dromedary camels to humans. Several known coronaviruses are circulating in animals that have not yet infected humans. Common signs of infection include respiratory symptoms, fever, cough, shortness of breath and breathing difficulties. In more severe cases, infection can cause pneumonia, severe acute respiratory syndrome, kidney failure and even death [1-3].

Standard recommendations to prevent infection spread include regular hand washing, covering mouth and nose when coughing and sneezing, thoroughly cooking meat and eggs. Avoid close contact with anyone showing symptoms of respiratory illness such as coughing and sneezing. A novel respiratory virus that originated in Wuhan, China, has spread to over 100 countries in Asia, Europe, North America and the Middle East. More than 100,000 have been infected, leaving many experts to fear a pandemic may already be underway.

a) China's factory output posts sharpest plunge in three decades in Jan-Feb.

b) Unprecedented Federal Reserve move fails to calm markets.

c) Spain, France follows Italy in imposing severe restrictions on movement.

Previous headlines:

a. UNCTAD warns of a $\$ 1$ trillion cost to the world economy.

b. Cryptocurrencies plunge.

c. Italy's entire population under quarantine measures.

d. Some key industries in Wuhan are told they can resume work.

\section{Coronavirus as universal crisis and stressful event}

Coronavirus is currently, one the most important and globe adjustment disorder. Occur when ordinary life stresses push people beyond their ability to cope effectively. Some signs that a person may be suffering from an adjustment disorders are extreme irritability, sleep 
disturbances, loss of appetite, physical complaints, anxiety, and depression.

The psychological symptoms that related to coronavirus are more complex for many reasons:

a) Currently, there are no treatment for this disease.

b) It is infectious disease.

c) It is epidemic disease.

d) Rumor and propaganda have been taken places about this disease.

e) Social and political policies have been focused and pay more attention all over the world.

These characteristics represents some urgent issues relating to this disease.

Questions and issues:

There are many hypotheses and issues relating to this universal health crisis:

a) Can we speak about psychological and biological war?

b) What about the social media in this crisis?

c) Is this medical/health problem and crisis exaggerated by rumor and propaganda?

d) What about the effectivity of the health services all over the world? e) Can we hypothesize: "coronavirus politics "?

Coronavirus is one of the most acute and chronic disease in the world. The most important symptoms that occur are: anxiety, and intense, sudden and unexpected panic. During the panic attack victim's experiences heart palpitations or chest pain, choking or smothering sensations, feeling of unreality and feeling of losing control. Panic attacks may also occur in many anxiety disorders, but in coronavirus disease seem to appear without warning. The most important coping skills with this globe disease is Quarantine, but this behavior has many consequences on the personality adjustment and social relation and interaction and may lead to stresses and frustration. The defense mechanism can be appearing effectively everyday life activity (regression, projections, rationalization, reaction formations, avoidance, daydreaming). In sum, cognitive and behavioral approach for coping with crises is very significant for children, adolescents, adults and elderly stage. We should be optimistic and hopeful because distorted thinking cause people to magnify ordinary threats and failure, leading to distress and susceptible to decrease psychoneuro immunology of personality [3-5].

\section{References}

1. Abdullah M (2020) Introduction to mental health. UK.

2. Abdullah M (2017) Medical psychology. University of Aleppo, Syria.

3. Pendleton (1998) Rumour research revisited and expanded. Language \& Communication 1(18): 69-86.

4. https://www.who.int/health-topics/coronavirus

5. https://www.nhs.uk/conditions/coronavirus-covid-19/ 